\title{
Corporate Social Responsibility for the Sustainability of Small Enterprises
}

\author{
G. Brindha, P. Devika
}

\begin{abstract}
Corporate Social Responsibility has proved as a significant segment in today's business environment as mounting efforts by the Small and Medium Enterprises are witnessed. Social role has become an area of all the enterprises irrespective of its size. According to Antonio Dias (2019) enterprises provide importance to CSR activities that helps them to maintain their business and to accomplish economic results. This research analyses the practice of CSR in stakeholder perspective who has the capacity to accelerate or decelerate the enterprise performance. Primary stakeholders considered in this study are employees, customers, community and environment. As far as SMEs are concerned, they are closely bonded to the local community where they operate which makes them to contribute more to the community development. Imran Ali (2010) in his research proved that CSR activities targeted towards employees improves organisation performance which in turn improves sustainability. Russo and Fouts (1997) concluded that commitment towards environment enhanced the profitability of the firm. Customers reward organisations that take efforts to produce quality products and stick to safety measures (Graafland and van de Ven, 2006). Structural Equation Modelling is used to identify the impact of CSR engagement of its primary stakeholders to attain sustainability.
\end{abstract}

Keywords: CSR, SMEs, Stakeholders, sustainability.

\section{INTRODUCTION}

Corporate Social Responsibility has emerged as an important area of focus as most of the organisation started valuing the social outcomes of their efforts. Setting social objectives have become an integral part of business strategy in order to establish them strongly as a responsible component of business environment. In this research, stakeholder theory is considered for analysing the impact of CSR engagement on sustainability. CSR can be best practised through the stakeholder theory which comprises of four major elements such as customers, community, employees and environment (Sweeny, 2007). The social and cause related efforts of business enterprises can be best witnessed thorough stake holder theory (Agle and Mitchell, 2008). All the business enterprises have its own impact on the society and environment irrespective of its size (Fox, 2005). Thus CSR is important for all the firms whether it is large or small (Moore and Spence, 2006).

\section{PROPOSED MODEL OF CSR FOR ENTERPRISE SUSTAINABILITY}

Revised Manuscript Received on September 14, 2019.

Dr. G. Brindha, Assistant Professor, Department of Business Administration with CA, Sri Krishna Arts and Science College, Coimbatore, Tamilnadu, India.(Email: brindhag@skasc.ac.in)

Mrs. P. Devika, Assistant Professor, Department of Business Administration with CA, Sri Krishna Arts and Science College, Coimbatore, Tamilnadu, India.(Email: devikap@skasc.ac.in).
This research obtained contributions from stakeholder theory in which the following elements i.e. Employees, Customers, Community, Environment were considered to build a CSR model. The activities carried out under each element were taken into account to measure its impact on the enterprise sustainability as a whole. The proposed model of Corporate Social Responsibility for enterprise sustainability is given below,

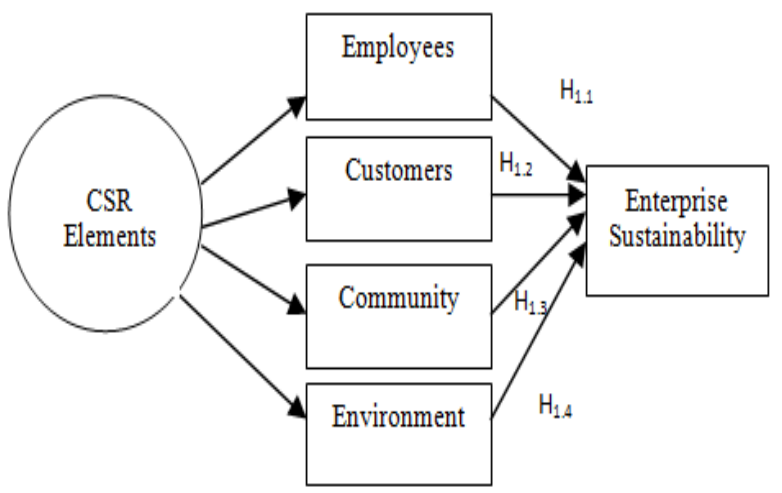

Fig. 2.1. CSR for Enterprise Sustainability

\section{RESEARCH HYPOTHESIS OF THE PROPOSED MODEL}

The above model comprising CSR elements and benefits to attain enterprise sustainability were tested using the formation of appropriate hypotheses and the same was tested to validate the above model. The following are the research hypotheses of the study,

H1.1: Commitment of SMEs towards employee has impact on the sustainability of the enterprise.

H1.2: Commitment of SMEs towards customer has impact on the sustainability of the enterprise.

H1.3: Commitment of SMEs towards community has impact on the sustainability of the enterprise.

H1.4: Commitment of SMEs towards environment has impact on the sustainability of the enterprise.

\section{METHODS}

The data were obtained from 360 owners of Small and Medium Enterprise in which the major sector covered in this research are textile and textile machinery, auto components, Jewellery and gems manufacturing, information technology and BPO and wet grinder manufacturing. The samples were drawn using random sampling technique by computer 
generated numbers. To explore the impact of CSR elements on enterprise sustainability, the developed model was tested using Structural Equation Modelling.

\subsection{Structural Equation Modelling}

Enterprises make an effort to pursue social goals only if they feel that it would lead to direct and indirect benefits. SMEs should believe that the benefits offered by undertaking CSR initiatives bring out new opportunities for excelling in their business. Thus the research attempts to measure how the commitment towards four CSR elements (independent variable) impacts enterprise sustainability (dependent variable) by considering their agreement on benefits for business sustainability.

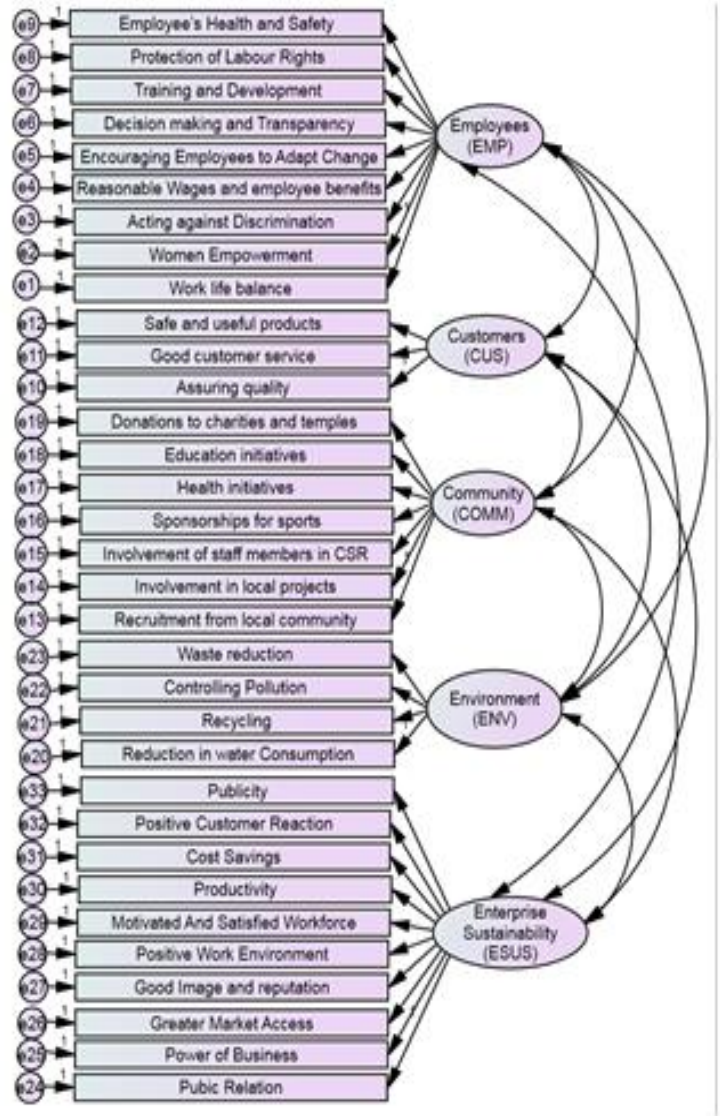

\section{Fig. 4.1 CSR FOR ENTERPRISE SUSTAINABILITY - FORMULATED MODEL}

\subsubsection{Measurement Model}

The measurement model comprised of 33 measurement items (indicators) related to five latent constructs which are: enterprise sustainability through CSR adoption (ESUS), employees (EMP), customer (CUS), community (COMM) and environment(ENV). The initial measurement model met Bollen's criteria, wherein each latent variable has at least two indicators and each observed variable is determined by one latent variable (Bollen, 1990). Thus, the measurement model is subjected to CFA using a maximum likelihood estimation procedure. The latent variables are allowed to correlate and measurement errors are uncorrelated.

\section{(i) Model Validation:}

The structured model can be validated using two measures such as convergent validity and discriminant validity. Convergent validity attempts to measure internal consistency within the constructs whereas discriminant validity ascertain that the variables of the study are related strongly to their own factor compared to the other factors in the model.

\section{a) Convergent validity:}

The results of the convergent validity in table 4.2 .2 shows that the standardised factor loadings of all the observed variables are well above the minimum cut-off limit of 0.6 with highest value of 0.95 and lowest value of 0.72 . The critical ratios ( $\mathrm{t}$ - values) are higher than $1.96(\mathrm{p}<0.001)$. The value of Cronbach's alpha exceeded 0.7 in all latent constructs showing higher internal reliability. Composite reliabilities of constructs exceed 0.6 limit ranging from 0.875 to 0.941 , reflecting adequate internal consistency.

Table I : Reliability And Convergent Validity Measures

\begin{tabular}{|c|c|c|c|c|c|c|c|}
\hline $\begin{array}{l}\text { Latent } \\
\text { construct }\end{array}$ & Item & $\begin{array}{l}\text { factor } \\
\text { Loadings } \\
\end{array}$ & $\begin{array}{l}(t- \\
\text { value })\end{array}$ & Sig. & CR & $\begin{array}{l}\mathbf{A V} \\
\mathbf{E}\end{array}$ & CA \\
\hline \multirow{11}{*}{$\begin{array}{l}\text { Enterprise } \\
\text { Sustainabilit } \\
\text { y }\end{array}$} & & & & & \multirow{11}{*}{$\begin{array}{l}0.9 \\
41\end{array}$} & \multirow{11}{*}{$\begin{array}{l}0.7 \\
62\end{array}$} & \multirow{11}{*}{$\begin{array}{l}0.9 \\
50\end{array}$} \\
\hline & ESUS1 & 0.80 & $-\cdots+$ & $\cdots$ & & & \\
\hline & ESUS2 & 0.86 & 28.24 & $* * *$ & & & \\
\hline & ESUS3 & 0.88 & 23.71 & $* * *$ & & & \\
\hline & ESUS4 & 0.91 & 24.32 & $* * *$ & & & \\
\hline & ESUS5 & 0.90 & 23.94 & **** & & & \\
\hline & ESUS6 & 0.82 & 19.88 & $* * *$ & & & \\
\hline & ESUS7 & 0.81 & 17.60 & $* * *$ & & & \\
\hline & ESUS8 & 0.85 & 19.02 & $* * *$ & & & \\
\hline & ESUS9 & 0.88 & 17.34 & $* * *$ & & & \\
\hline & $\begin{array}{l}\text { ESUS1 } \\
0\end{array}$ & 0.87 & 27.73 & $* * *$ & & & \\
\hline \multicolumn{8}{|l|}{ Employees } \\
\hline & & 0.80 & ----** & ---- & 0.9 & 0.6 & 0.9 \\
\hline & \multicolumn{4}{|l|}{ EMP1 } & & & \\
\hline & EMP2 & 0.85 & 18.67 & $* * *$ & & & \\
\hline & EMP3 & 0.86 & 15.34 & $* * *$ & & & \\
\hline & EMP4 & 0.83 & 14.67 & $* * *$ & & & \\
\hline & EMP5 & 0.77 & 13.21 & $* * *$ & & & \\
\hline & EMP6 & 0.93 & 17.41 & $* * *$ & & & \\
\hline & EMP7 & 0.89 & 17.16 & $* * *$ & & & \\
\hline & EMP8 & 0.73 & 13.46 & $* * *$ & & & \\
\hline & EMP8 & 0.81 & 13.52 & $* * *$ & & & \\
\hline \multirow[t]{3}{*}{ Customer } & CUS1 & 0.89 & ---_* & $\begin{array}{l}--- \\
\end{array}$ & \multirow[t]{3}{*}{0.8} & \multirow[t]{3}{*}{0.7} & \multirow[t]{3}{*}{0.8} \\
\hline & CUS2 & 0.92 & 27.59 & $* * *$ & & & \\
\hline & CUS3 & 0.75 & 20.89 & $* * *$ & & & \\
\hline \multirow{7}{*}{$\begin{array}{l}\text { Communit } \\
\text { y }\end{array}$} & COM1 & 0.74 & - -.-.* $^{*}$ & ---- & \multirow[t]{7}{*}{0.8} & \multirow[t]{7}{*}{0.7} & \multirow[t]{7}{*}{0.8} \\
\hline & COM2 & 0.95 & 21.06 & $* * *$ & & & \\
\hline & COM3 & 0.85 & 20.20 & $* * *$ & & & \\
\hline & COM4 & 0.74 & 18.40 & $\begin{array}{l}* * * * \\
*\end{array}$ & & & \\
\hline & COM5 & 0.80 & 19.87 & *** & & & \\
\hline & COM6 & 0.92 & 13.69 & $* * *$ & & & \\
\hline & COM7 & 0.91 & 17.39 & $* * *$ & & & \\
\hline \multirow{4}{*}{$\begin{array}{l}\text { Environme } \\
\text { nt }\end{array}$} & ENV1 & 0.72 & ---_* & ---- & \multirow[t]{4}{*}{0.8} & \multirow[t]{4}{*}{0.6} & \multirow[t]{4}{*}{0.9} \\
\hline & ENV2 & 0.73 & 17.25 & $* * *$ & & & \\
\hline & ENV3 & 0.88 & 12.40 & $* * *$ & & & \\
\hline & ENV4 & 0.93 & 12.11 & $* * *$ & & & \\
\hline
\end{tabular}

Note: $C R=$ composite reliability, $A V E=$ average variance extracted $C A=$ Cronbach's alpha, ${ }^{*}$ depicts Regression weight $1 ; * * * p<0.001$.

\section{b) Discriminant validity:}

The variables within the parent factor should correlate well with each other. In table 4.2.3, the condition for discriminant validity for the constructs enterprise sustainability, employees, customers, community and environment is achieved as the diagonal values is greater

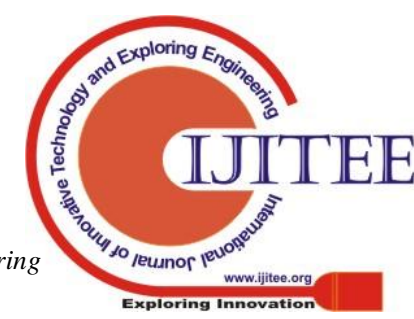


than the value given in its corresponding row and column. Thus all diagonal values exceeded the inter-construct correlations, reflecting high level of discriminant validity of the constructs.

Table II : Discriminant Validity of Latent Constructs

\begin{tabular}{|c|c|c|c|c|c|}
\hline Construct & EECA & EMP & CUS & $\mathrm{COM}$ & ENV \\
\hline EECA & 0.87 & & & & \\
\hline EMP & $0.56^{4 * *}$ & 0.85 & & & \\
\hline CUS & $0.45^{* 4 *}$ & $0.56^{* * *}$ & 0.83 & & \\
\hline COM & $-0.19^{* * *}$ & $-0.33^{*+*}$ & $-0.24^{+4 *+}$ & 0.80 & \\
\hline ENV & $0.15^{* *}$ & $0.23^{* * *}$ & $0.25^{* * *}$ & -0.08 & 0.86 \\
\hline \multicolumn{6}{|c|}{$\begin{array}{l}\text { Note: Diagonal values in bold represent square root of } \\
\text { average variance extracted (AVE) and off diagonal values are } \\
\text { inter-construct correlations. }\end{array}$} \\
\hline \multicolumn{6}{|c|}{$\begin{array}{l}* p<0.05, * *_{p}<0.01, * * * p<0.001 ; \text { all other correlations are } \\
\text { insignificant. }\end{array}$} \\
\hline
\end{tabular}

\subsubsection{Evaluation of structural model}

Confirmed measurement model is specified into the structural model based on the relationships proposed in the research model of this study. The structural model is evaluated to assess the model fit and to test the hypothesised casual relationships. Overall, the structural model shows a good fit with the data. The analysis of structural model generated acceptable model fit indices: absolute fit measures $(\mathrm{GFI}=0.918, \mathrm{AGFI}=0.912, \mathrm{RMSEA}=0.039$ and $\mathrm{RMR}=$ $0.012)$; the incremental fit measures (NFI $=0.940, \mathrm{CFI}=$ 0.968 , IFI, $=0.966$, and TLI $=0.964)$ and the parsimony fit measures $(\mathrm{PNFI}=0.929, \mathrm{PCFI}=0.954, \mathrm{PGIF}=0.964$ and PRATIO $=0.682$ ) that surpassed the minimum recommended values suggested by previous studies.

\subsubsection{Path analysis (Hypothesis testing)}

After establishing an acceptable structural model, the statistical significance of the parameter estimates from SEM are evaluated by examining path estimates and critical ratio (C.R) or t-value. The results are hypothesis testing are given below,

Table III : Results of Hypothesis Testing

\begin{tabular}{|l|l|l|l|l|l|}
\hline Hypothesis & $\begin{array}{l}\text { Path } \\
\text { coefficient }\end{array}$ & $\begin{array}{l}\text { Standard } \\
\text { Error }\end{array}$ & $\mathrm{t}$ & $\mathrm{P}$ & Result \\
\hline $\mathrm{H} 1: \mathrm{EMP} \rightarrow \mathrm{EECA}(+)$ & 0.56 & 0.036 & 3.77 & 0.00 & Accepted \\
\hline $\mathrm{H} 2: \mathrm{CUS} \rightarrow \mathrm{EECA}(+)$ & 0.32 & 0.014 & 3.88 & 0.00 & Accepted \\
\hline $\mathrm{H} 3: \mathrm{COMM} \rightarrow \mathrm{EECA}(+)$ & 0.40 & 0.046 & 2.74 & 0.00 & Accepted \\
\hline $\mathrm{H} 4: \mathrm{ENV} \rightarrow \mathrm{EECA}(+)$ & 0.23 & 0.058 & 2.76 & 0.00 & Accepted \\
\hline
\end{tabular}

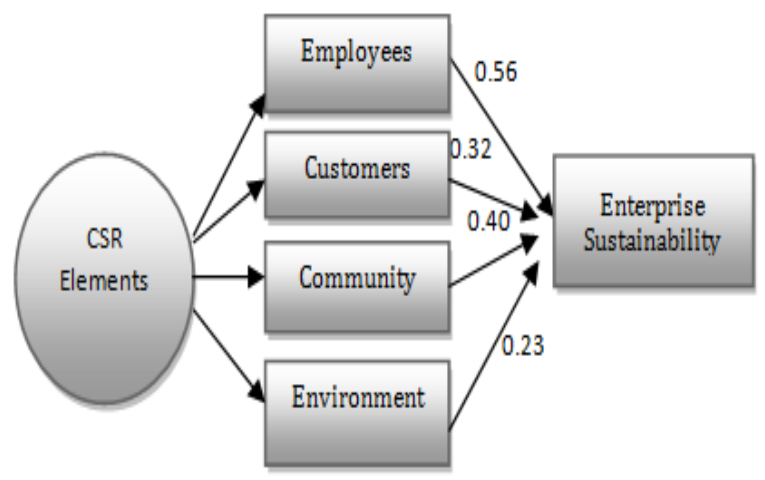

Fig. 4.2. Path Analysis for Hypothesis Testing
It could be inferred from the above table that the overall measurement results involving the elements employees, customer, community and environment provides higher contribution to the enterprise sustainability. This states that sustainability in enterprise activities can be achieved if the enterprise has higher level of commitment towards the four CSR elements. The major contributor of the model to enterprise sustainability is employee commitment which is followed by community commitment, customer commitment and environment commitment respectively. Thus commitment towards the betterment of employees improves the sustainability of the enterprise to a greater extent compared to commitment towards other CSR elements.

\section{RESULTS \& DISCUSSION}

\subsection{Implications of the Research:}

Acting socially responsible improves the chances of excelling in business. So every enterprise should have a social objective in accordance with their enterprise objective that paves way for new business opportunities. This perspective should be clearly comprehended by the small enterprises to have an innovative approach in setting up their social goals. Accomplishment of such objectives is very indispensable for the growth of their business. Small enterprises should anticipate social responsibility as a gain and not a distraction from their main business activity.

It was identified from the analysis that SMEs showed less interest in environment related initiatives. Though there is a growing need for undertaking recycling mechanisms, they were not able to initialize it due to lack of adequate technology and cost constraints. While allocating budget for the corporation, government should allot funds to initiate such activities and encourage SMEs to actively take part in it.

Government can adopt green legislations to promote the use of green technologies in the enterprises. Indian Green Building Council focuses to build a green city to reduce the energy consumption of buildings. The smart cities project insists the enterprises to procure raw materials from the local suppliers so that effect of carbon footprint would be reduced by avoiding transportation of raw materials from longer distance.

India is a surging economy that is trying to overcome the social issues related to community, poverty, child rights, women empowerment and unemployment. Thus it is hot bed which needs unique strategies to overcome the social hurdles. Government can induce responsiveness by allowing the small enterprises to champion CSR to attain sustainability. The intrinsic strength of the small champions should be recognized by the government bodies to provide effective support in attaining their social ambitions.

\subsection{Conclusion}

The research study substantiated that Small and Medium Enterprises have a very strong role in making meaningful contribution to the society. In spite of notable differences in their abilities, their mounting effort for social transformation is appreciable.

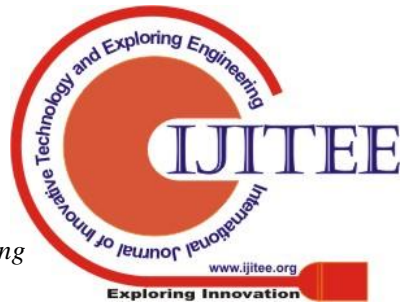


Small and Medium Enterprises believe that stakeholders are the major reason for their business existence. This attitude makes them to willingly participate in CSR to wipe out social disturbances. Despite an additional activity, CSR foster enterprise sustainability which is very essential to make continuous contribution for welfare activities. These small champions have a great role to play in the future of $\mathrm{CSR}$ as they going to be the contributor of socio economic revolution.

\subsection{Scope for Future Research}

The research considered only the four major of stakeholders of the business. The other stakeholders involved in the enterprise activities can also be considered in the further research. In addition to stakeholder theory, future research can be continued by offering insights to other CSR models. Different CSR models can be compared to suggest a new innovative model that better suits the social role of SMEs.

\section{REFERENCES}

1. António Dias, Lúcia Lima Rodrigues, Russell Craig, Maria Elisabete Neves, "Corporate social responsibility disclosure in small and medium-sized entities and large companies," Social Responsibility Journal, Vol. 15 Issue: 2, pp.137-154, 2019, https://doi.org/10.1108/SRJ05-2017-0090

2. Ali, I., Rehman, K.U., Ali, S., Yousaf, J., \& Zia, M, "Corporate social responsibility influences, employee commitment and organizational performance," African Journal of Business Management Vol. 4(12), pp. 27962801, 4 October, 2010

3. Ashridge "Catalogue of CSR Activities: A Broad Overview," Ashridge Centre for Business and Society: Hertfordshire, 2005.

4. Agle B. and Mitchell R, "Introduction: Recent Research and New Questions," Business Ethics Quarterly 18(2), 153-90, 2008

5. Baron D, "Private Politics, Corporate Social Responsibility and Integrated Strategy," Journal of Economics and Management Strategy 10, 7-45, 2001

6. Clarkson M, "A Stakeholder Framework for Analysing and Evaluating Corporate Social Performance," Academy of Management Review 20(1), 92-118, 1995.

7. Cooper S., Crowther D. and Davies M, "Shareholder or Stakeholder Values: The Development of Indicators for the Control and Measurement of Performance," Chartered Institute of Management Accountants: London, 2001.

8. Edgeman, Rick, Eskildsen \& Jacob, "Modeling and Assessing Sustainable Enterprise Excellence". Business Strategy and the Environment. 23 (3): 173. doi:10.1002/bse.1779, 2013.

9. Fox T, "Small and Medium Sized Enterprises (SMEs) and Corporate Social Responsibility: A Discussion Paper," IIED, 2005.

10. Gildea R, "Consumer Survey Confirms Corporate Social Action Affects Buying Decisions," Public Relations Quarterly (Winter), 20-1, 2001.

11. Godfrey P, "The Relationship between Corporate Philanthropy and Shareholder Wealth: A Risk Management Perspective," Academy of Management Review 30(4), 777-98, 2005.

12. Graafland, J. and B. W. van de Ven, "Strategic and Moral Motivation for Corporate Social Responsibility," Journal of Corporate Citizenship 22 (Summer), 111-123, 2006.
13. Hair Jr, J. F., Hult, G. T. M., Ringle, C., \& Sarstedt, M, "A primer on partial least squares structural equation modeling (PLS-SEM)," Sage Publications, 2013.

14. Hopkins M, "The Planetary Bargain: Corporate Social Responsibility Matters," Earthscan Publications Ltd, London, 2003. 